\title{
Neural differentiation of allogenic mixed-cultured rat bone mesenchymal stem cells
}

\author{
Jun Zhou ${ }^{1}$, Huilin Yang ${ }^{1 *}$, Jiannong Cen ${ }^{2}$ \\ ${ }^{1}$ Department of Orthopaedic Surgery, The First Affiliated Hospital of Soochow University, Suzhou, China \\ ${ }^{2}$ Jiangsu Institute of Hematology, The First Affiliated Hospital of Soochow University, Suzhou, China \\ Email: *yanghl1960@hotmail.com
}

Received 10 March 2013; revised 16 April 2013; accepted 24 April 2013

Copyright (C) 2013 Jun Zhou et al. This is an open access article distributed under the Creative Commons Attribution License, which permits unrestricted use, distribution, and reproduction in any medium, provided the original work is properly cited.

\begin{abstract}
Many studies showed that bone mesenchymal stem cells (BMSCs) can transdifferentiate to neural cell in vitro. The purpose of this study was to investigate the mixed-culture of allogenic rat BMSCs in vitro, and to perform neural differentiation potential characterization. Rat BMSCs were isolated and cultured by plastic adherence and density gradient centrifugation respectively, and the 3rd passage cells were harvested and mixed-cultured with same concentration. The second passage cells of the mixed-cultured cells were obtained to perform Wright-Gemsa staining for morphological observation, to identify the surface marker of CD29, CD45, CD90 by flow cytometry and induced to differentiate into neural cell, then performed immunocytochemistry of Nestin, NSE and GFAP. Results showed that after Wright-Giemsa staining, the mixed-cultured cells displayed typical spindle-shape, presented layered and whirlpool-like growth; and the mixed-cultured cells were positive for CD29 and CD90, but negative for CD45 by flow cytometry. After induction, the mixed-cultured cells appeared morphological changes of neuron and glial cell, and were positive expression of Nestin, neuron specific enolase (NSE) and glial fibrillary acidic protein (GFAP). The results demonstrated that the mixed-cultured allogenic rat BMSCs can be induced into neural cell such as neuron and glial cell in vitro.
\end{abstract}

Keywords: Bone Mesenchymal Stem Cells; Neural Differentiation; Nestin; Neuron Specific Enolase; Glial Fibrillary Acidic Protein

\section{INTRODUCTION}

With intensive study to central nervous system (CNS)

\footnotetext{
${ }^{*}$ Corresponding author.
}

regeneration, especially with the demonstration of the existence of cells in the developing and adult nervous system that can be isolated and grown in vitro, where they behave as neural stem cells (NSCs), has provided new understanding to neural regeneration and treatment of neural diseases [1]. NSCs are capable of undergoing expansion and differentiating into neurons, astrocytes, and oligodendrocytes in vitro [2,3] and in vivo [4,5], whereas the well-known technical and ethical difficulties of NSCs sources severely limit clinical utility. Therefore, to find a new resource of NSCs is necessary to transplantation therapy of CNS. Many studies have reported that bone mesenchymal stem cells (BMSCs) are capable of transdifferentiating to neural cell types under appropriate experimental conditions in vitro [6-8], BMSCs even could spontaneously differentiate into neural precursor cells after long-term culture [9]. Neurological diseases and CNS trauma have potential loss of neurons. Although NSCs can differentiate into neural cells, repair capacity of neural tissue after injury is limited because NSCs are localized to selected region. Marrow cells are readily accessible, overcoming the risks of obtaining NSCs from the brain. Moreover, BMSCs grow rapidly in culture and not limited by ethical considerations; therefore, it may be useful in the treatment of a wide variety of neurological diseases and CNS trauma. However, neural regeneration needs a lot of cells, sometimes autologous BMSCs can not meet the need, this allows us to consider the utilization of allogenic BMSCs as transplantation cells resouces. The most two frequently used methods for BMSCs isolation are plastic adherence $[6,8,9]$ and density gradient centrifugation $[10,11]$. Different methods have different defects and virtues. Plastic adherence is an easy method for BMSCs obtaining on the basis of their plastic adherence characteristics, but it is difficult to get pure BMSCs. Cells isolated by density gradient centrifugation method are relatively more pure but with lower reproductive activity. In the present study, we 
investigated the mixed-culture of allogenic SpragueDawley (SD) rat BMSCs (rBMSCs) isolated by plastic adherence and density gradient centrifugation respectively in vitro, performed immunocytochemistry of nestin, NSE and GFAP, to confirm that mixed-cultured allogenic BMSCs can be induced into neural cell such as neuron and glial cell in vitro.

\section{MATERIALS AND METHODS}

\subsection{Animals}

Two male SD rats (6 weeks old, body weight was $93 \mathrm{~g}$ and 96 g respectively) were supplied by the Medical Experimental Animal Center, Soochow University, China (license No. SYXK (Su) 2002-0037). Ethical approval was obtained from the Ethical Committee of Soochow University. Protocols were in accordance with the Principles of Laboratory Animal Care (NIH Publication No. 85-23, revised 1985).

\section{2. rBMSCs Isolation and Culture}

Primary rBMSCs were isolated as previously described by Jendelová [12] and the experience of Jiangsu Institute of Hematology. Briefly, two male SD rats were sacrificed by overdose chloral hydrate injection $(1600 \mathrm{mg} / \mathrm{kg}$ body weight). Tibias and femurs were dissected free and the proximal and distal ends were removed to reveal the marrow cavity which was aspirated with $10 \mathrm{ml}$ of BMSCs growth medium: low glucose Dulbecco's modified Eagle's medium (LG-DMEM) $+10 \%$ fetal bovine serum (FBS) (all from Gibco, USA) through a $21 \mathrm{G}$ needle. The aspirate was centrifuged at $1000 \mathrm{rpm}$ for $5 \mathrm{~min}$ twice. The cell pellet obtained (containing both haematopoietic cells and BMSCs) was then suspended in BMSCs growth medium. The suspension of one rat was then cultured in four $25 \mathrm{~cm}^{2}$ plastic culture flasks and incubated at $37^{\circ} \mathrm{C}$ with $5 \%$ humidified carbon dioxide $\left(\mathrm{CO}_{2}\right)$ for $24 \mathrm{~h}$. Flasks were washed with phosphate buffered saline (PBS) to leave an adherent layer of cells containing rBMSCs. The suspension of another rat was diluted 2:1 with layered over Ficoll (Ficoll-Paque, The Second Reagents Factory of Shanghai, China). After centrifugation at $2000 \mathrm{rpm}$ for $20 \mathrm{~min}$, the mononuclear cell layer was collected from the gradient interface and washed with BMSCs growth medium, then centrifuged at $1000 \mathrm{rpm}$ for $5 \mathrm{~min}$ twice. The cells were cultured in two $25 \mathrm{~cm}^{2}$ plastic culture flasks and incubated at $37^{\circ} \mathrm{C}$ with $5 \%$ humidified $\mathrm{CO}_{2}$. After $48 \mathrm{~h}$, nonadherent cells were removed by replacing the medium.

Fresh culture medium was replaced every 3 - 4 days. When the cultures approached near confluency, the cells were harvested and digested with $0.25 \%$ trypsin $/ 1 \mathrm{mM}$ ethylene diamine tetraacetic acid (EDTA) (Gibco) and diluted $1: 2$ or $1: 3$ per passage for further expansion. Af- ter this cycle was repeated three times, rBMSCs obtained with two different methods were harvested and mixedcultured by $1: 1$ and repeated this cycle. The second passage of mixed-cultured rBMSCs was obtained to perform Wright-Giemsa staining (fast Wright-Giemsa Stain Kit, Baso, Taiwan, China) for morphological observation: removed medium, washed with PBS, added solution A incubated for $5 \mathrm{~min}$, then added solution B incubated for 5 min, washed with PBS, cleared water with absorbent paper.

\subsection{Flow Cytometric Analysis}

The second passages of mixed-cultured rBMSCs were characterized by flow cytometry. In brief, cells were trypsinized and washed with fluorescence activated cell sorting (FACS) buffer, consisting of $\mathrm{Ca}^{++} / \mathrm{Mg}^{++}$-free PBS, $13.6 \mathrm{mM}$ tri-sodium citrate and $1 \%$ bovine serum albumin (BSA) (Sigma, USA). After centrifugation at 2000 rpm for $5 \mathrm{~min}$ at $4^{\circ} \mathrm{C}$, cells were suspended in FACS buffer and divided into 4 tubes with $100 \mu \mathrm{l}$ suspension at a concentration of $1 \times 10^{6} / 100 \mu \mathrm{l}$ for each antibody tested. Cells were then labeled with $10 \mu \mathrm{L}$ of fluorescein conjugated monoclonal antibody or standard control at $4^{\circ} \mathrm{C}$ for 30 min: the first tube, PE/Cy5 CD29 standard control (BioLegend, USA) and PE CD45 standard control (Caltag, USA); the second tube, PE/Cy5 CD29 (BioLegend) and PE CD45 (Caltag); the third tube, PE/Cy5 CD29 standard control and PE CD90 standard control (eBioscience, USA); the fourth tube, PE/Cy5 CD29 and PE CD90 (eBioscience). The labeled cells were analyzed by flow cytometry within $2 \mathrm{~h}$. At least 20,000 cells for each sample were acquired and analyzed. PE/Cy5 colouration is red, the wave length of excitation light is $488 \mathrm{~nm}$, the maximum wave length is $667 \mathrm{~nm}$; PE colouration is yellow, the wave length of excitation light is $488 \mathrm{~nm}$, the maximum wave length is $578 \mathrm{~nm}$.

\subsection{Neural Differentiation}

Neural differentiation is according to the experience of Jiangsu Institute of Hematology and Woodbury et al. [6]. In brief, subconfluent mixed-cultured cells were maintained in BMSCs growth medium. Twenty-four hours prior to neural induction, media were replaced with preinduction medium: LG-DMEM $+10 \%$ FBS $+1 \mu \mathrm{M}$ Fibroblast Growth Factor-basic (b-FGF) (Peprotech, Israel). To initiate neural differentiation, the pre-induction media were removed, and the cells were washed with PBS and transferred to neural induction medium: LG-DMEM + 2\% Dimethyl sulphoxide (DMSO) (Sigma, USA) + 200 $\mu \mathrm{M}$ butylated hydroxyanisole (BHA) (Sigma).

\subsection{Immunocytochemistry}

After neural induction for $24 \mathrm{~h}$, media were removed, the 
mixed-cultured cellse were fixed with $4 \%(\mathrm{v} / \mathrm{v})$ paraformaldehyde for 30 minutes at room temperature and washed 3 times with PBS, cleared water with absorbent paper. Non-specific binding was blocked by a $40 \mathrm{~min}$ treatment with goat serum fluid at $30^{\circ} \mathrm{C}$. The cells were then incubated for $24 \mathrm{~h}$ with primary antibody (nestin 1:150; NSE 1:150; GFAP 1:150, all from Boster Bioengineering Limited Company, China) at $4^{\circ} \mathrm{C}$, washed 3 times with PBS, then incubated for 40 min with biotinconjugated second antibody (goat anti-rabbit 1:50) at $37^{\circ} \mathrm{C}$, washed 3 times with PBS, incubated for $30 \mathrm{~min}$ with Horseradish Peroxidase-Streptavidin dilution buffer at $37^{\circ} \mathrm{C}$, washed 3 times with PBS, 3,3'-diaminobenzidine (DAB) served as chromagen.

\section{RESULTS}

\section{1. rBMSCs Isolation and Culture}

The primary rBMSCs obtained by bone marrow plastic adherence method are uneven in shape, but with excellent reproductive activity. The primary BMSCs obtained by density gradient centrifugation method are fairly uniform in shape, but with lower reproductive activity. After 3 passages, the cells obtained by these two methods both

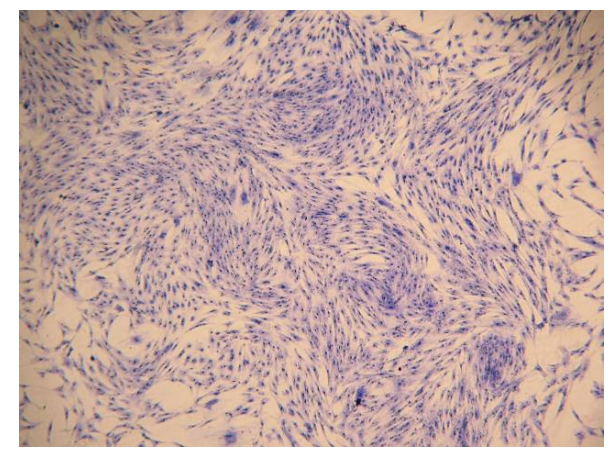

(a)

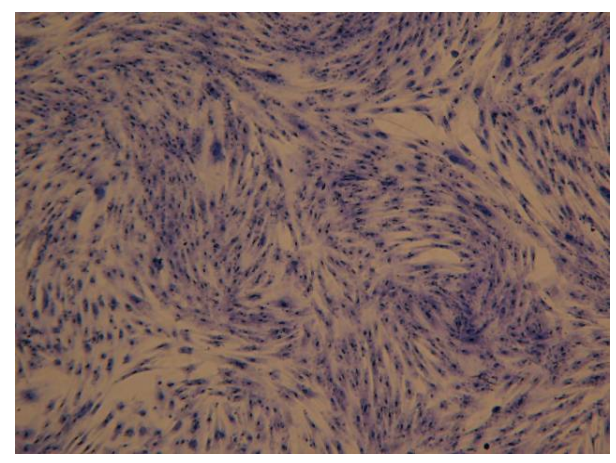

(b)

Figure 1. Morphology of allogenic mixedcultured BMSCs: cells displayed typical spindle-shaped cells, presented layered and whirlpool-like growth (Wright-Giemsa staining): (a) Magnification $\times 100$; (b) Magnification $\times 200$. got relative purification. The mixed-cultured BMSCs were good in reproductive activity and relatively uniform in shape. After Wright-Giemsa staining, the mixed-cultured BMSCs displayed typical spindle-shaped cells, presented layered and whirlpool-like growth (Figure 1).

\subsection{Flow Cytometric Analysis}

Using flow cytometric analysis, the mixed-cultured BMSCs were positive for the surface antigens CD29 and CD90, but negative for CD45 and CD29, CD45, CD90 standard control (Figure 2).

\subsection{Neural Differentiation}

Before neural induction, there were no obvious changes in the morphology of the mixed-cultured rBMSCs, cells still displayed spindle-shaped cells, presented layered and whirlpool-like growth (Figure 3(a)). While exposure to neural induction medium for $3 \mathrm{~h}$, there were apparent morphological changes in some of the cells, the cells exhibited contracted cell contour with peripheral halo and process-like extensions, changed from flat, elongated, spindle-shaped cells to rounded cells with several branching extensions. After $24 \mathrm{~h}$ neural induction, almost all of the mixed-cultured cells displayed neural morphology, with rounded cell body, and their processes formed extensive networks (Figure 3(b)).

\subsection{Immunocytochemistry}

Immunocytochemistry results showed that induced cells with neural-like morphology were positively stained for nestin, NSE and GFAP (Figure 4).

\section{DISCUSSION}

According to many previous studies, CD29 and CD90 were regarded as positive cell-surface markers for MSCs, while CD45 was regard as negative surface markers [1316]. The mixed-cultured cells used in this study were positive for CD29, CD90 and negative for CD45, indicated that the isolated BMSCs showed typical MSC characteristics.

BMSCs have shown the potential to transdifferentiate into neural lineage under appropriate experimental conditions in vitro [6-8]. The properties of neural differentiation make BMSCs an attractive target for therapeutic applications in neurological diseases and CNS trauma. However, neural regeneration needs a lot of cells, sometimes autologous BMSCs can not meet the need, this allows us to consider the utilization of allogenic BMSCs as transplantation cells resouces. In this study, we investigated the mixed-culture of allogenic SD rat BMSCs in vitro, performed immunocytochemistry of nestin, NSE and GFAP, to confirm that mixed-cultured allogenic 


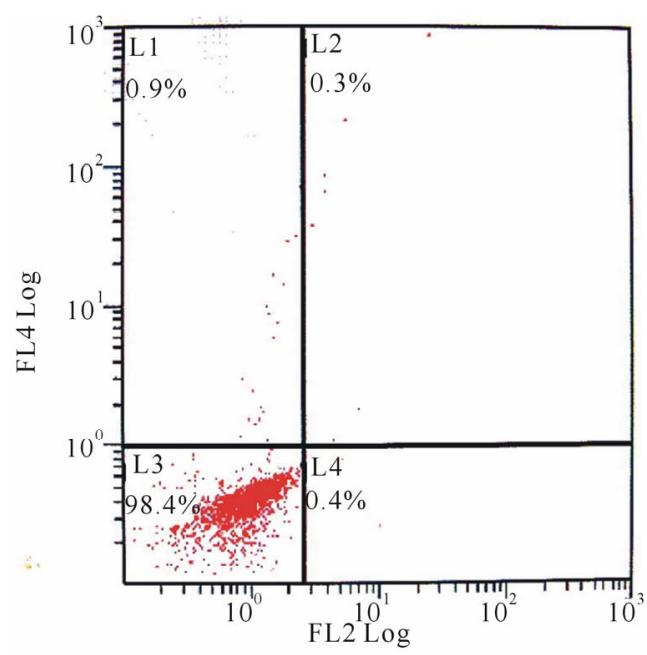

(a)

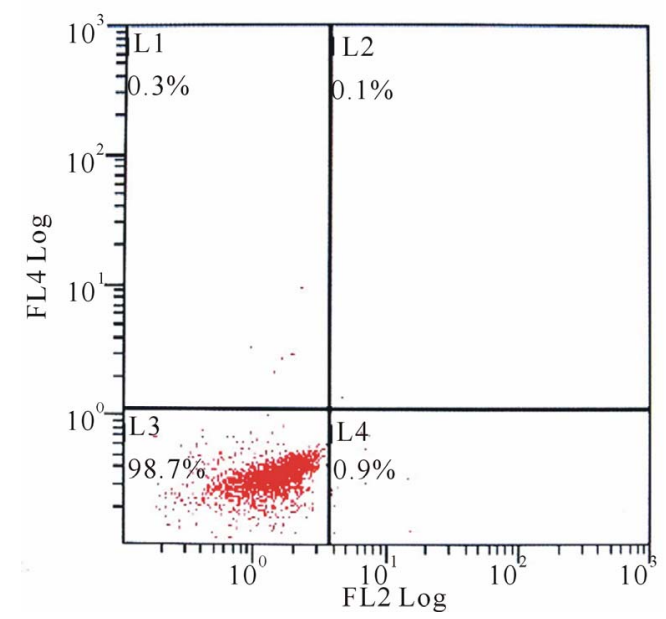

(c)

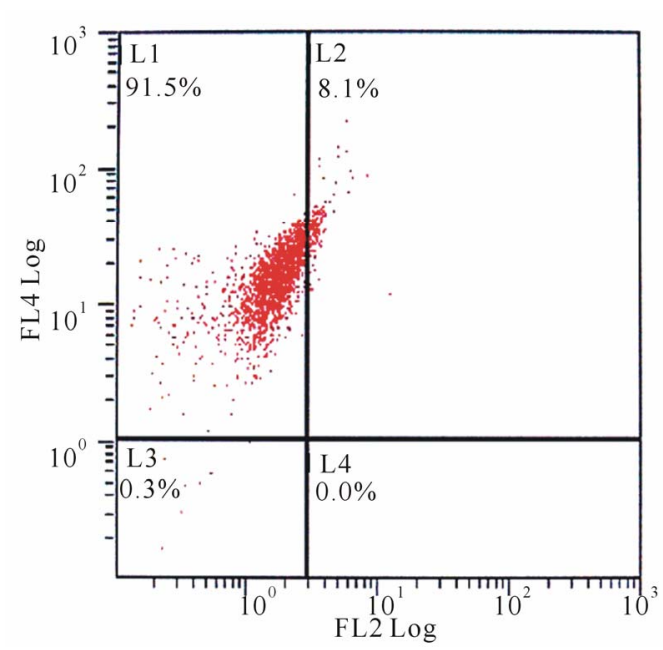

(b)

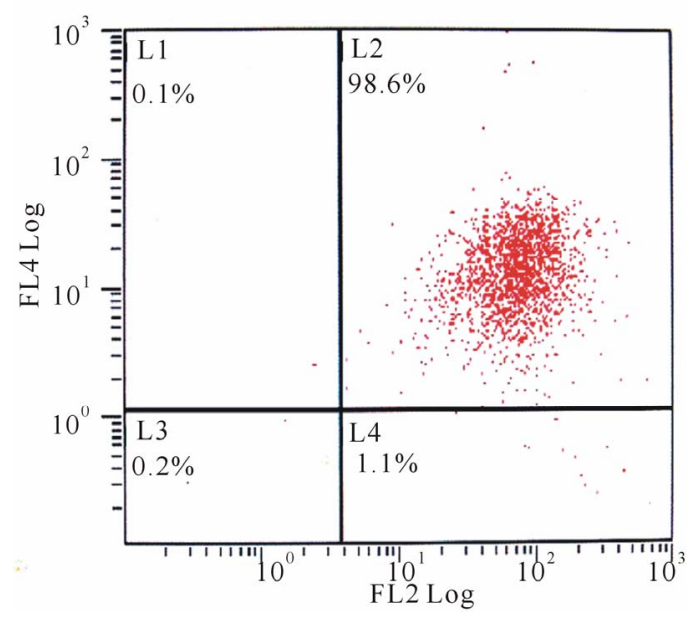

(d)

Figure 2. The flow cytometry of mixed-cultured BMSCs showed: (a) CD29 control (-), CD45 control (-); (b) CD29 (+), CD45 (-); (c) CD29 control (-), CD90 control (-); (d) CD29 (+), CD90 (+).

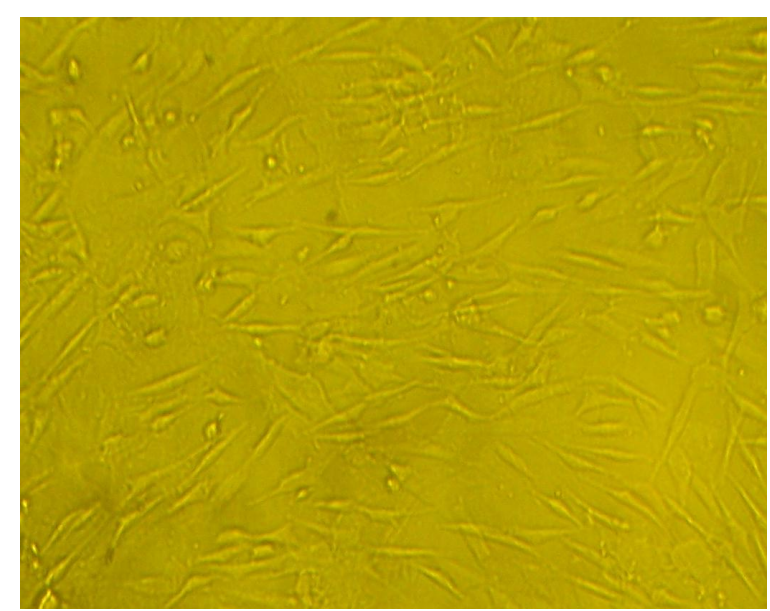

(a)

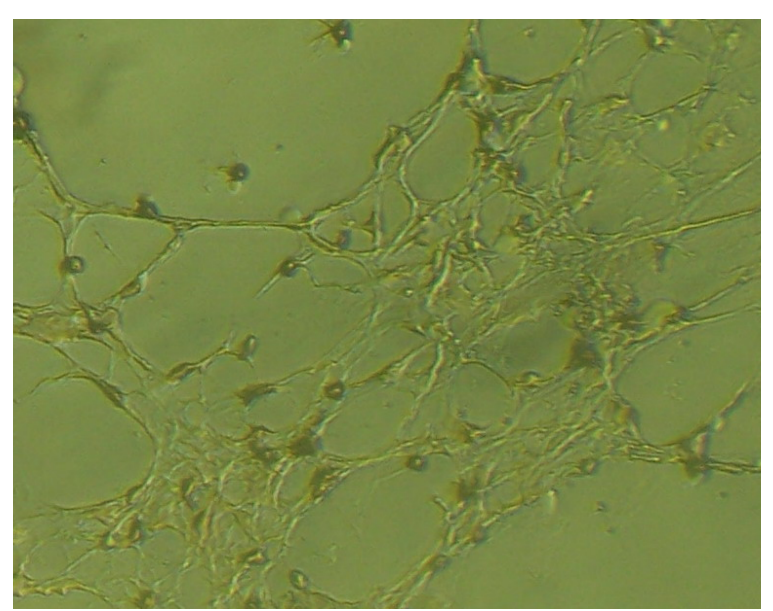

(b)

Figure 3. morphology of the mixed-cultured rBMSCs: (a) Pre-induction mixed-cultured BMSCs still displayed spindleshaped cells, presented layered and whirlpool-like growth (magnification $\times 100$ ); (b) Post-induction mixed-cultured BMSCs showed neural morphology, such as rounded cell body and processes formed extensive networks (magnification $\times 100$ ). 


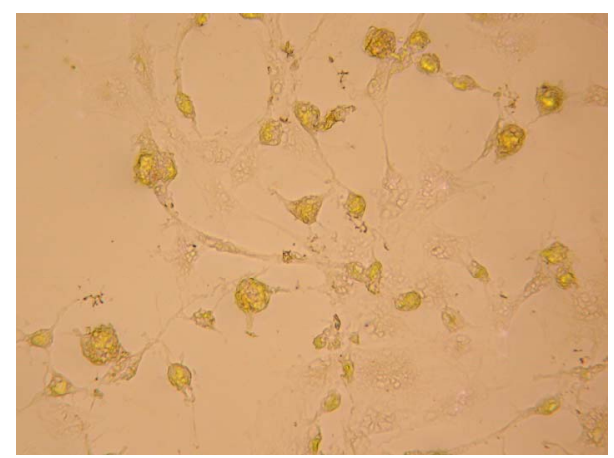

(a)

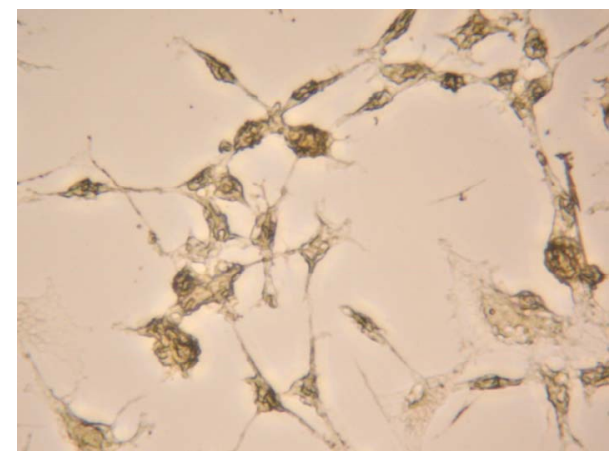

(b)

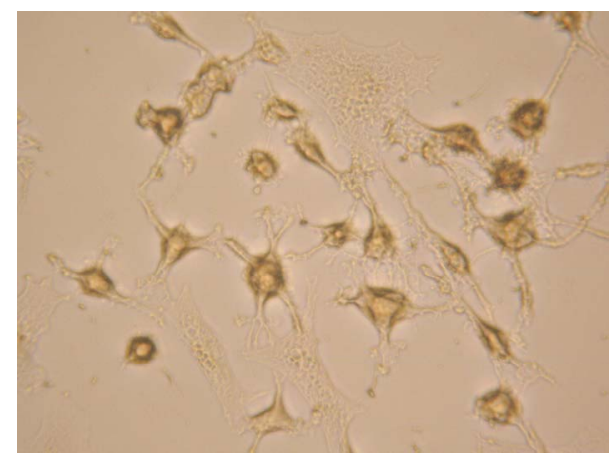

(c)

Figure 4. After neural induction, mixed-cultured cells showed: (a) Neuronal morphological characteristics, cell bodies became spherical and refractile, nestin (+) (magnification $\times 200$ ); (b) Processes continued to elaborate, displaying primary and secondary branches, NSE (+) (magnification $\times 200$ ); and (c) Processes formed extensive networks, GFAP $(+)$ (magnification $\times 200$ ).

BMSCs can be induced into neural cell such as neuron and glial cell in vitro.

Immunocytochemistry results showed that induced cells with neural-like morphology were positively stained for nestin, NSE and GFAP. nestin belongs to the intermediate filament (class VI) family and is transiently expressed in various progenitors during development, such as neuroectodermal stem cells and the oligodendroglial lineage [17]. During embryogenesis, nestin is ex- pressed in migrating and proliferating cells, whereas in adult tissues, nestin is mainly restricted to areas of regeneration [18]. NSE is a marker of neuron [19], and GFAP is a marker of glial cell [20]. The induced cells positive expressed nestin, NSE and GFAP, clearly demonstrated that mixed-cultured allogenic BMSCs can be induced into neural cell such as neuron and glial cell in vitro.

Woodbury et al. [6] reported that BMSCs undergo transformation into cells with neuron-like phenotypes expressing NSE, neuronal nuclei (NeuN), neurofilament-M (NF-M) and tau. Following treatment is processed with neuronal pre-induction medium consisting of DMEM/ $20 \% \mathrm{FBS} / 1 \mathrm{mM} \beta$-mercaptoethanol (BME) for $24 \mathrm{~h}$, then treated with neuronal induction medium composed of DMEM/1 - 10 mM BME or DMEM/2\% DMSO/200 mM BHA.

Lei et al. [7] use three different methods to induce neural differentiation of BMSCs: BME, serum-free medium and co-cultivation with fetal mouse brain astrocytes. These three methods led to a non-identical results: in serum-free medium, BMSCs mainly differentiated into neuron-like cells, expressing neuronal marker $\mathrm{NeuN}$, and BME can promote this process. After co-cultured with astrocytes, BMSCs leaned to differentiate into GFAP $(+)$ cells.

Tseng et al. [9] observed that after continuous culture for 6 weeks, $(32.3 \pm 6.3) \%$ BMSCs positive expressed nestin. After cultured in serum-free DMEM/F12 and 20 $\mathrm{ng} / \mathrm{ml} \mathrm{b-FGF} \mathrm{for} 4$ days, these nestin-positive cells expressed neuron-like morphology and neuron-specific markers neurofilament-H (NF-H), beta III-tubulin, tau, and neurotransmitter Gamma-aminobtric acid (GABA). These results demonstrated that neural precur- sors could be obtained from long-term cultured BMSCs.

These studies made us to reconsider and study whether true neural differentiation of BMSCs takes place following treatment with growth factor and chemical induction medium. According to the experience of Jiangsu Institute of Hematology, Woodbury et al. [6], we determined neural pre-induction medium (LG-DMEM $+10 \% \mathrm{FBS}+1$ $\mu \mathrm{M}$ b-FGF) and neural induction medium (LG-DMEM + $2 \%$ DMSO $+200 \mu \mathrm{M}$ BHA). It is reported that b-FGF promotes transdifferentiation, maintenance of a transdifferentiated state, or cell survival and is involved in the development and maintenance of the nervous system [21]. Tao et al. [22] found that partially differentiated bone marrow cells could not be maintained in culture beyond 3 days post-cytokine withdrawal, suggesting that neuronal differentiation of BMSC under serum-free and feeder cell-free conditions is cytokine dependent. The combination of three growth factors to be crucial: b-FGF to induce neuronal differentiation, epidermal growth factor (EGF) to maintain cell proliferation and differentia- 
tion, and plateletderived growth factor (PDGF) to support neuronal differentiation [22]. Both DMSO and BHA are antioxidants, the exact mechanism of them to promote BMSCs differentiate towards neural linage is unclear, possibly related to the trigger of transcripton which determined differentiation direction [23].

Our study revealed that within $3 \mathrm{~h}$ of treatment with the induction medium, mixed-cultured cells had neural morphological change. This change was distinguished by rounded and highly refractive cell bodies with neuritelike processes that terminated in structures resembling growth cones and processes formed extensive networks. These findings suggested that the mixed-cultured BMSCs might have differentiated to neural cells. This differentiation potential need appropriate experimental conditions, induction medium may provided these conditions. However, neural-like cells differentiated from mixed-cultured allogenic BMSCs how to possess function of neural cell and the exact mechanism of neural differentiation of mixed-cultured allogenic BMSCs need further study.

\section{CONCLUSION}

The results of the present study suggest that the mixedcultured allogenic rBMSCs can be induced into neural cell such as neuron and glial cell in vitro.

\section{ACKNOWLEDGEMENTS}

This study was supported in part by the Natural Science Foundation of Jiangsu Province Youth Fund Project (Grant No. BK2012169), Natural Science Fund for Colleges and Universities in Jiangsu Province (Grant No. 09KJD320007) and Pre-research Project of Soochow University (Grant No. Q3122828). We thank Miss Danhong Shen and Hailan Dai for their help with flow cytometry.

\section{REFERENCES}

[1] Lindvall, O., Kokaia, Z. and Martinez-Serrano, A. (2004) Stem cell therapy for human neurodegenerative disorders-How to make it work. Nature Medicine, 10, S42S50. doi:10.1038/nm1064

[2] Leipzig, N.D., Wylie, R.G., Kim, H. and Shoichet, M.S. (2011) Differentiation of neural stem cells in three-dimensional growth factor-Immobilized chitosan hydrogel scaffolds. Biomaterials, 32, 57-64. doi:10.1016/j.biomaterials.2010.09.031

[3] Rak, K., Wasielewski, N.V., Radeloff, A., Völkers, J., Scherzed, A., Jablonka, S., Hagen, R. and Mlynski, R. (2011) Isolation and characterization of neural stem cells from the neonatal rat cochlear nucleus. Cell Tissue Research, 343, 499-508. doi:10.1007/s00441-010-1118-x

[4] McMahon, S.S., Albermann, S., Rooney, G.E., Shaw, G., Garcia, Y., Sweeney, E., Hynes, J., Dockery, P., O’Brien, T., Windebank, A.J., Allsopp, T.E. and Barry, F.P. (2010) Engraftment, migration and differentiation of neural stem cells in the rat spinal cord following contusion injury. $C y$ totherapy, 12, 313-325. doi:10.3109/14653241003695018

[5] Mitrecić, D., Nicaise, C., Gajović, S. and Pochet, R. (2010) Distribution, differentiation, and survival of intravenously administered neural stem cells in a rat model of amyotrophic lateral sclerosis. Cell Transplant, 19, 537-548. doi: 10.3727/096368910X498269

[6] Woodbury, D., Schwarz, E.J., Prockop, D.J. and Black, I.B. (2000) Adult rat and human bone marrow stromal cells differentiate into neurons. Journal of Neuroscience Research, 61, 364-370.

doi:10.1002/1097-4547(20000815)61:4<364::AID-JNR2 $>3.0 . \mathrm{CO} ; 2-\mathrm{C}$

[7] Zhao, L., Lin, Y.D., Ma, J., Sun, Y.Y., Zeng, S.J., Zhang, X.W. and Zuo, M.X., (2007) Culture and neural differentiation of rat bone marrow mesenchymal stem cells in vitro. Cell Biology International, 31, 916-923. doi:10.1016/j.cellbi.2007.02.006

[8] Bronzi, D., Bramanti, V., Tomassoni, D., Laureanti, F., Grasso, S., Li Volsi, G. and Avola, R. (2010) Neural markers expression in rat bone marrow mesenchymal stem cell cultures treated with neurosteroids. Neurochemical Research, 35, 2154-2160. doi:10.1007/s11064-010-0283-3

[9] Tseng, P.Y., Chen, C.J., Sheu, C.C., Yu, C.W. and Huang, Y.S. (2007) Spontaneous differentiation of adult rat marrow stromal cells in a long-term culture. Journal of Veterinary Medical Science, 69, 95-102. doi:10.1292/jvms.69.95

[10] Zhang, L., Kahn, C.J., Chen, H.Q., Tran, N. and Wang, X. (2008) Effect of uniaxial stretching on rat bone mesenchymal stem cell: Orientation and expressions of collagen types I and III and tenascin-C. Cell Biology International, 32, 344-352. doi:10.1016/j.cellbi.2007.12.018

[11] Huang, Y., Jia, X., Bai, K., Gong, X. and Fan, Y. (2010) Effect of fluid shear stress on cardiomyogenic differentiation of rat bone marrow mesenchymal stem cells. $\mathrm{Ar}$ chives of Medical Research, 41, 497-505. doi:10.1016/j.arcmed.2010.10.002

[12] Jendelová, P., Herynek, V., DeCroos, J., Glogarová, K., Andersson, B., Hájek, M. and Syková, E. (2003) Imaging the fate of implanted bone marrow stromal cells labeled with superparamagnetic nanoparticles. Magnetic Resonance in Medicine, 50, 767-776. doi:10.1002/mrm.10585

[13] Dominici, M., Le Blanc, K., Mueller, I., Slaper-Cortenbach, I., Marini, F., Krause, D., Deans, R., Keating, A., Dj, P. and Horwitz, E. (2006) Minimal criteria for defining multipotent mesenchymal stromal cells. The International Society for Cellular Therapy position statement. Cytotherapy, 8, 315-317. doi:10.1080/14653240600855905

[14] Harting, M., Jimenez, F., Pati, S., Baumgartner, J. and Cox Jr., C. (2008) Immunophenotype characterization of rat mesenchymal stromal cells. Cytotherapy, 10, 243-253. doi:10.1080/14653240801950000

[15] Halfon, S., Abramov, N., Grinblat, B. and Ginis, I. (2011) Markers distinguishing mesenchymal stem cells from fibroblasts are downregulated with passaging. Stem Cells and Development, 20, 53-66. doi:10.1089/scd.2010.0040 
[16] Takemitsu, H., Zhao, D., Yamamoto, I., Harada, Y., Michishita, M. and Arai, T. (2012) Comparison of bone marrow and adipose tissue-derived canine mesenchymal stem cells. BMC Veterinary Research, 31, 150. doi:10.1186/1746-6148-8-150

[17] Vanderwinden, J.M., Gillard, K., De Laet, M.H., Messam, C.A. and Schiffmann, S.N. (2002) Distribution of the intermediate filament nestin in the muscularis propria of the human gastrointestinal tract. Cell Tissue Research, 309, 261-268. doi:10.1007/s00441-002-0590-3

[18] Wiese, C., Rolletschek, A., Kania, G., Blyszczuk, P., Tarasov, K.V., Tarasova, Y., Wersto, R.P., Boheler, K.R. and Wobus, A.M. (2004) Nestin expression-A property of multi-lineage progenitor cells? Cellular and Molecular Life Sciences, 61, 2510-2522. doi:10.1007/s00018-004-4144-6

[19] Pillai, R., Scintu, F., Scorciapino, L., Carta, M., Murru, L., Biggio, G., Cabras, S., Reali, C. and Sogos, V. (2006) Human astrocytes can be induced to differentiate into cells with neuronal phenotype. Experimental Cell Research, 312, 2336-2346. doi:10.1016/j.yexcr.2006.03.031

[20] Tohill, M., Mantovani, C., Wiberg, M. and Terenghi, G.
(2004) Rat bone marrow mesenchymal stem cells express glial markers and stimulate nerve regeneration. Neuroscience Letters, 362, 200-203. doi:10.1016/j.neulet.2004.03.077

[21] Timmer, M., Cesnulevicius, K., Winkler, C., Kolb, J., Lipokatic-Takacs, E., Jungnickel, J. and Grothe, C. (2007) Fibroblast growth factor (FGF)-2 and FGF receptor 3 are required for the development of the substantia nigra, and FGF-2 plays a crucial role for the rescue of dopaminergic neurons after 6-hydroxydopamine lesion. Journal of Neuroscience, 27, 459-471. doi:10.1523/JNEUROSCI.4493-06.2007

[22] Tao, H., Rao, R. and Ma, D.D. (2005) Cytokine-induced stable neuronal differentiation of human bone marrow mesenchymal stem cells in a serum/feeder cell-free condition. Development, Growth \& Differentiation, 47, 423433. doi:10.1111/j.1440-169X.2005.00810.x

[23] Justesen, J., Stenderup, K. and Kassem, M.S. (2001) Mesenchymal stem cells. Potential use in cell and gene therapy of bone loss caused by aging and osteoporosis. Ugeskr Laeger, 163, 5491-5495. 